\title{
Decreased mTOR signaling pathway in human idiopathic autism and in rats exposed to valproic acid
}

\author{
Chiara Nicolini ${ }^{1}$, Younghee $\mathrm{Ahn}^{2}$, Bernadeta Michalski ${ }^{1}$, Jong M Rho ${ }^{2}$ and Margaret Fahnestock ${ }^{1 *}$
}

\begin{abstract}
Background: The molecular mechanisms underlying autistic behaviors remain to be elucidated. Mutations in genes linked to autism adversely affect molecules regulating dendritic spine formation, function and plasticity, and some increase the mammalian target of rapamycin, MTOR, a regulator of protein synthesis at spines. Here, we investigated whether the Akt/mTOR pathway is disrupted in idiopathic autism and in rats exposed to valproic acid, an animal model exhibiting autistic-like behavior.
\end{abstract}

Methods: Components of the mTOR pathway were assayed by Western blotting in postmortem fusiform gyrus samples from 11 subjects with idiopathic autism and 13 controls and in valproic acid versus saline-exposed rat neocortex. Additionally, protein levels of brain-derived neurotrophic factor receptor (TrkB) isoforms and the postsynaptic organizing molecule PSD-95 were measured in autistic versus control subjects.

Results: Full-length TrkB, PI3K, Akt, phosphorylated and total mTOR, p70S6 kinase, elF4B and PSD-95 were reduced in autistic versus control fusiform gyrus. Similarly, phosphorylated and total Akt, mTOR and 4E-BP1 and phosphorylated S6 protein were decreased in valproic acid- versus saline-exposed rats. However, no changes in 4E-BP1 or elF4E were found in autistic brains.

Conclusions: In contrast to some monogenic disorders with high rates of autism, our data demonstrate down-regulation of the Akt/mTOR pathway, specifically via p70S6K/elF4B, in idiopathic autism. These findings suggest that disruption of this pathway in either direction is widespread in autism and can have adverse consequences for synaptic function. The use of valproic acid, a histone deacetylase inhibitor, in rats successfully modeled these changes, implicating an epigenetic mechanism in these pathway disruptions.

Keywords: Human postmortem, Autism, Valproate, Signal transduction, TrkB, PSD-95

\section{Introduction}

Autism is a neurodevelopmental disorder characterized by social communication and interaction impairments and restricted, repetitive patterns of behavior [1]. While it is believed that defects in the establishment and maintenance of functional neuronal networks due to synaptic/ spine dysfunction underlie the clinical symptomatology of autism, the molecular mechanisms causing these defects remain unknown. Several studies point to the Akt/mTOR pathway, which regulates translation at dendritic spines

\footnotetext{
* Correspondence: fahnest@mcmaster.ca

'Department of Psychiatry \& Behavioural Neurosciences, McMaster University, 1280 Main Street West, Hamilton, ON L8S 4K1, Canada

Full list of author information is available at the end of the article
}

$[2,3]$, as a potential molecular substrate of autism. Indeed, mutations in genes encoding Akt-mTOR cascade components cause disorders with high rates of autism [2-5]. Additionally, autism-like phenotypes have been observed in Eif4ebp2 knockout and eIF4E-overexpressing mice [6], both downstream mTOR effectors regulating protein translation. These findings strengthen the hypothesis that disruptions in the mTOR pathway contribute to autism neuropathology, likely by negatively affecting spines, which are perturbed in subjects with autism [7]. Nonetheless, protein products of these genes have not been examined in idiopathic autism.

Valproic acid (VPA) is widely used as an antiepileptic drug $[8]$ and for the treatment of mood disorders $[9,10]$. 
Maternal exposure to VPA at the time of neural tube closure causes autism-like symptoms in humans [11-13]. Clinical effects of maternal challenge with VPA, including impaired social interactions, stereotypical hyperactivity and sensory/communication deficits have been reproduced in both rats and mice [14-17]. In particular, prenatally VPA-exposed rats exhibit not only autisticlike behaviors $[18,19]$ but also anatomical and molecular alterations similar to human autism including reductions in cerebellar volume and numbers of Purkinje cells $[20,21]$, altered monoamine levels [22], decreased expression of the autism-linked gene, neuroligin 3 [23], and perturbed cortical connectivity along with abnormal synapse formation and pruning [24,25]. VPA's ability to inhibit histone deacetylase (HDAC) has been associated with autistic-like behavioural, anatomical and biochemical deficits in mice prenatally exposed to this drug [17], supporting the hypothesis that epigenetic mechanisms contribute to autism etiology. Indeed, mounting evidence highlights the involvement of epigenetic factors in synaptic dysfunction and disrupted cortical circuitry causing autistic traits $[26,27]$. However, the affected signal transduction pathways remain to be identified.

In the present study, we investigated whether the Akt/ mTOR pathway, which is disrupted in monogenic disorders with high rates of autism, is altered in idiopathic autism. We specifically examined idiopathic autism, that is, subjects without known genetic causes of autism and without related disorders on the spectrum. We also examined whether VPA exposure in rats affects this pathway. We measured protein levels of mTOR and its upstream/downstream effectors in brains from subjects with idiopathic autism versus control subjects and in VPA- versus saline-exposed rats. Contrary to disruptions seen in Fragile X syndrome, tuberous sclerosis, PTENrelated macrocephaly and neurofibromatosis type 1 , developmental disorders with high rates of autism, we demonstrated decreased Akt/mTOR pathway in both patients with idiopathic autism and in VPA-exposed rats. These findings support the hypothesis that alterations in Akt/mTOR signaling in either direction contribute to autistic behavior, likely by affecting dendritic spines. Additionally, similar molecular changes in VPA-exposed rats suggest that epigenetic changes may underlie the synaptic deficits characteristic of idiopathic autism.

\section{Materials and methods}

\section{Human brain tissue samples}

All experimental protocols were approved by the Research Ethics Board of McMaster University. Frozen samples consisting of eleven post-mortem fusiform gyrus samples from subjects with idiopathic autism (3 females, 8 males) and thirteen control brain samples (3 females, 10 males) were provided to us by the Autism Speaks'
Autism Tissue Program (Princeton, NJ) via the Harvard Brain Tissue Resource Centre (Belmont, MA) and the National Institute of Child Health and Human Development (NICHD) Brain and Tissue Bank (University of Maryland, Baltimore, MD) and were stored at $-80^{\circ} \mathrm{C}$ before use. Clinical information about each tissue sample was obtained through the Autism Tissue Program online portal [http://www.autismbrainnet.com/about-us/portal/] [28] (Tables 1 and 2). Samples were matched as much as possible for age, gender and post-mortem interval (PMI). There were no significant differences between groups for these variables [28]. Cause of death, however, differed between samples. It was not possible to match the cause of death due to the scarcity of available tissue. All of the tissues were from fusiform gyrus because this area is implicated in autism [29-32]. The diagnosis of autism was confirmed using the Autism Diagnostic InterviewRevised [33] post-mortem through interviews with the parents and/or caregivers. Samples from subjects with known genetic causes of autism spectrum and related disorders (Rett, Asperger etc.) were excluded. Subject characteristics are shown in Tables 1 and 2.

\section{Animal brain tissue samples}

All experimental protocols were in compliance with the University of Calgary Conjoint Faculties Research Ethics Approval Board. Pregnant Wistar Han rats (The Jackson Laboratory, Bar Harbor, ME, USA or Charles River Laboratories, Wilmington, MA, USA) were ordered on embryonic day 3 (E3). The sodium salt of valproic acid (Sigma, St. Louis, MO, USA) was dissolved in $0.9 \%$ saline to achieve a concentration of $250 \mathrm{mg} / \mathrm{ml}$. The dosing volume was $500 \mathrm{mg} / \mathrm{kg}$. On E12.5, treated dams received a single intraperitoneal (i.p.) injection of $500 \mathrm{mg} / \mathrm{kg}$ VPA sodium salt, while control dams were injected with only saline $[17,34]$. Rats were born and reared in a quiet, temperature-controlled room and entrained to a 12-h light-dark cycle. Male pups from each group were sacrificed between P35-38. As the fusiform gyrus, which is part of the temporal and occipital lobes in humans, is not present in rodents, the lateral temporal neocortex was collected for analysis.

\section{RNA isolation and RT-PCR}

Seven autism and eleven control samples from fusiform gyrus were used for qRT-PCR. RNA was isolated as described in reference [28]. Yield and purity of total cellular RNA were determined by absorbance at 260 and $280 \mathrm{~nm}$, and RNA integrity was verified by agarose gel electrophoresis. cDNA was generated as previously described [28]. Samples containing double-distilled water in place of reverse transcriptase were included as negative controls (no-RT). 
Table 1 Characteristics of autism tissue samples

\begin{tabular}{llllllll}
\hline Sample ID\# & CASE \# & Age (years) & Gender & PMI (hours) & Primary cause of death & ADI-R & Drug treatment history \\
\hline A1 & AN01093 & 56 & Male & 19.48 & Anoxic Encephalopathy & 48 & N/A \\
A2 & UMB1174 & 7 & Female & 14 & Seizure, Hypotension & 44 & Depakote, Dilantin, Tegretol \\
A3 & AN00764 & 20 & Male & 23.7 & Auto Trauma & 50 & Minocin \\
A4 & AN08792 & 30 & Male & 20.3 & Gastrolntestinal Bleeding & 41 & $\begin{array}{l}\text { Phenobarbital, Mysoline, Dilantin, Depakote, } \\
\text { Cisapride, Clorazepate, Prolosec, Propulsid, }\end{array}$ \\
& & & & & & & Reglan, Tranxene \\
A5 & AN06420 & 39 & Male & 13.95 & Cardiac Tamponade & 41 & $\begin{array}{l}\text { Synthroid, Depakote, Risperidol, Paxil, } \\
\text { Blood pressure medication }\end{array}$ \\
A6 & AN00493 & 27 & Male & 8.3 & Drowning & & Synthroid \\
A7 & AN08873 & 5 & Male & 25.5 & Asphyxia Due To Drowning & 47 & Prozac \\
A8 & UMB797 & 9 & Male & 13 & Drowning & 50 & Desipramine \\
A9 & UMB1182 & 9 & Female & $\mathbf{2 4}$ & Smoke Inhalation & - & N/A \\
A10 & AN16641 & 9 & Male & 27 & Seizure Disorder & 46 & Clonidine, Depakote, Dilantin, \\
& & & & & & Lamictal, Ritalin, Tegretol \\
A11 & AN16115 & 11 & Female & 12.88 & Seizure \& Drowning in Tub & 44 & Adderall, Dexadrine, Dilantin, Klonopin, \\
& & & & $\mathbf{1 8 . 3}$ & & & Lamictal, Tegretol, Topomax \\
& Mean & $\mathbf{2 0 . 1}$ & & $\mathbf{1 . 8}$ & & &
\end{tabular}

N/A = Information Not Available; PMI = Post Mortem Interval; ADI-R = Autism Diagnostic Interview-Revised.

Real-time qPCR was performed as described [28]. Forward primer, 5'-GGC CCA GAT GCT GTC ATT AT-3', and reverse primer, $5^{\prime}$-TTC TGC TCA GGA CAG AGG TT-3', were used to detect full length TrkB (TrkB-FL), while truncated TrkB (TrkB-T1) was detected using forward primer, 5'-TGC CTT TTG GTA ATG CTG TTT-3', and reverse primer, $5^{\prime}$-GGC TTC ATA TAG TAC AGC CTC CA-3'. Lastly, detection of the truncated isoform
TrkB-Shc was performed using forward primer, 5'-GGC CCA GAT GCT GTC ATT AT-3', and reverse primer, 5' -AGG CAT GGA TTT AGC CTC CT-3'. Copy numbers using absolute quantification and PCR efficiencies were calculated with MXPro Mx3000P Software (Stratagene). Only experiments in which the real-time PCR efficiency was between 90\%-100\% and standard curves yielded a $R^{2}>0.990$ were used for analysis.

Table 2 Characteristics of control tissue samples

\begin{tabular}{lllllll}
\hline Sample ID\# & CASE \# & Age (years) & Gender & PMI (hours) & Primary cause of death & Secondary cause of death \\
\hline C1 & AN12552 & 56 & Male & 23.61 & Traumatic asphyxia and crush injury & Cardiac Arrest \\
C2 & AN17344 & 46 & Male & 25.9 & Unknown & N/A \\
C3 & AN14771 & 30 & Male & 23 & Cardiac Arrhythmia & N/A \\
C4 & UMB818 & 27 & Male & 10 & Multiple injuries & Accident \\
C5 & AN17425 & 16 & Male & 26.16 & Unknown & N/A \\
C6 & AN15240 & 36 & Female & 18.08 & Unknown & N/A \\
C7 & AN19760 & 28 & Male & 23.25 & Unknown & N/A \\
C8 & AN12240 & 51 & Male & 4.75 & Ml & N/A \\
C9 & AN10606 & 56 & Male & 23 & Myocardial infarction & N/A \\
C10 & UMB1706 & 8 & Female & 20 & Rejection of Cardiac Allograft Transplantation & N/A \\
C11 & UMB1860 & 8 & Male & 5 & Cardiac Arrhythmia & N/A \\
C12 & UMB1407 & 9 & Female & 20 & Asthma & N/A \\
C13 & UMB1649 & 20 & Male & 22 & Multiple injuries & \\
& Mean & $\mathbf{2 8 . 5}$ & & $\mathbf{1 8 . 8}$ & & \\
\end{tabular}




\section{Protein extraction from brain tissue}

Rat tissues were homogenized in RIPA buffer (Thermo Scientific, Rockford, IL, USA) with protease (complete, Mini, EDTA-free) and phophatase (PhosSTOP) inhibitor cocktail tablets (Roche, Indianapolis, IN, USA). A similar homogenization buffer [35] was used for human samples. Homogenates were sonicated, incubated on ice for 15-30 min and then centrifuged at $13000 \times \mathrm{g}$ for $10-$ $20 \mathrm{~min}$ at $4^{\circ} \mathrm{C}$ to precipitate insoluble debris. The supernatants were collected and protein concentrations were determined using the BCA protein assay kit (Thermo Scientific, Rockford, IL, USA) or the $\mathrm{DC}^{\mathrm{TM}}$ protein assay (Bio-Rad Laboratories, Mississauga, Ontario, Canada) as described by the manufacturer. Rat tissue lysates were pooled in order to handle a large number of samples that exceeded the lane capacity of a gel, while human homogenates were not pooled. Sample protein concentrations were adjusted to $4 \mu \mathrm{g} / \mu \mathrm{l}$ (rat) or $1.5-3.5 \mu \mathrm{g} / \mu \mathrm{l}$ (human) for Western blotting.

\section{Western blotting and densitometry}

10 to $40 \mu \mathrm{g}$ total protein (depending on the target) was separated on $8 \%-12 \%$ sodium dodecyl sulfate (SDS)polyacrylamide gels or Mini-PROTEAN ${ }^{\circledR}$ Precast Gels (Bio-Rad, Hercules, CA, USA) under reducing conditions and transferred to polyvinylidene fluoride (PVDF) membranes (Bio-Rad, Hercules, CA, USA). Membranes were then blocked with a 1:1 solution of phosphatebuffered saline (PBS) pH7.4 and Odyssey Blocking Buffer (BB) (Cedarlane, Burlington, Ontario, Canada) or $5 \%$ nonfat milk in Tris-buffered saline solution containing 0.1\% Tween 20 (TBS-T) for 1 hour. After blocking, the blots were probed overnight at $4^{\circ} \mathrm{C}$ with the following primary antibodies: TrkB (Cell Signaling Technology, Danvers, MA, USA, diluted 1:700), PI3K p85, Akt, phospho-Akt, mTOR, phospho-mTOR (Ser2448), 4EBP1, phospho-4E-BP1, eIF4E, eIF4B, S6, phospho-S6, GFAP, ßIII-Tubulin (Cell Signaling Technology, diluted 1:1000), p70S6K (Santa Cruz Biotechnology, diluted 1:500), and PSD-95 (Millipore, diluted 1:1000). Membranes were simultaneously probed with mouse monoclonal anti- $\beta$-actin antibody (Sigma, diluted 1:5000 or Cell Signaling Technology, diluted 1:1000) as a loading control.

After washing with TBS-T, rat blots were incubated with the secondary antibody horseradish peroxidase (HRP)-conjugated goat anti-rabbit (Bio-Rad, Hercules, CA, USA) for 1 hour at room temperature, washed with TBS-T, exposed to Hyper film ECL (Amersham Pharmacia Biotech, Carlsbad, CA, USA) and ultimately visualized using the enhanced chemiluminescence (ECL) detection system. Bands were detected and quantified using a ChemiDOC MP gel imaging system (Bio-Rad, Hercules, CA, USA).
After washing with PBS containing 0.5\% Tween-20 (PBS-T), human tissue blots were incubated with the secondary antibodies IRDye 680-conjugated goat antirabbit and IRDye $800 \mathrm{CW}$-conjugated goat anti-mouse (LI-COR Biosciences, Lincoln, NE, USA; diluted 1:8000) for 1 hour at room temperature, washed with PBS-T and scanned using an Odyssey ${ }^{\oplus}$ Infrared Imaging System (LI-COR Biosciences). Band intensities were quantified by densitometry with local background subtraction using LI-COR ${ }^{\oplus}$ Odyssey Software, version 2.0.

\section{Statistical analysis}

Each Western blot for human tissue contained a standard curve consisting of different amounts of protein per lane (from 1 to $80 \mu \mathrm{g}$ ) from a single normal human cortex sample to allow normalization between blots and to ensure that the sample loading amount was in the linear range of detection for all targets tested.

For both RT-PCR and Western blot experiments, each human or rat sample was expressed as a ratio to its corresponding $\beta$-actin value.

Differences in the target mRNA or protein levels between autism, VPA and respective control samples were calculated by 2 -tailed Student's $t$-test with statistical significance set at $\mathrm{p}<0.05$.

\section{Results}

Decreased PI3K p85, Akt, mTOR, phospho-mTOR, p70S6K and elF4B protein expression in idiopathic autism

Akt/mTOR pathway protein expression levels were examined in the fusiform gyrus of subjects with idiopathic autism versus control subjects. Fusiform gyrus is an area of the brain implicated in face discrimination and perception difficulties of autistic subjects [29,32]. Western blotting revealed a statistically significant decrease in PI3K p85 and Akt (* $\mathrm{p}=0.03$, Figure 1A,B; ${ }^{*} \mathrm{p}=0.03$, Figure 1C,D; 2-tailed $t$ tests) protein in the fusiform gyrus of autistic subjects relative to controls.

Total and phosphorylated mTOR were also decreased in autism versus control brain $\left({ }^{* * *} \mathrm{p}=0.003\right.$, Figure 2A; **** $\mathrm{p}=0.0003$, Figure 2B; 2-tailed $t$ tests).

We next examined the mTOR downstream effector pathways p70S6K/eIF4B and 4E-BP1/eIF4E involved in local dendritic protein translation. A statistically significant decrease in $\mathrm{p} 70 \mathrm{~S} 6 \mathrm{~K}$ and eIF4B protein was found $\left(* * \mathrm{p}=0.002\right.$, Figure $3 \mathrm{~A}, \mathrm{~B} ;{ }^{*} \mathrm{p}=0.02$, Figure $3 \mathrm{C}, \mathrm{D}$; 2 -tailed $t$ tests) in the fusiform gyrus of autistic subjects relative to controls. However, there were no significant differences in protein expression levels of 4E-BP1 or eIF4E ( $p=0.6$, Figure 3E,F; $p=0.4$, Figure 3G,H; 2tailed $t$ tests) in the fusiform gyrus of control $v s$. autism subjects. 

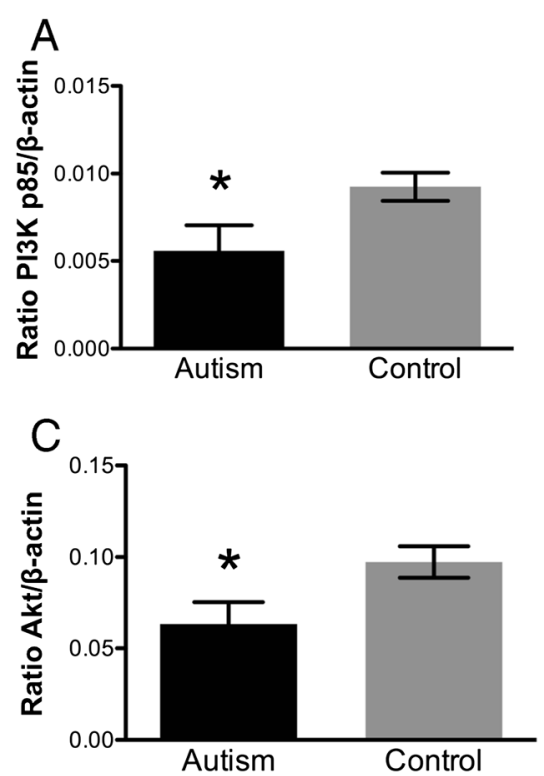

B

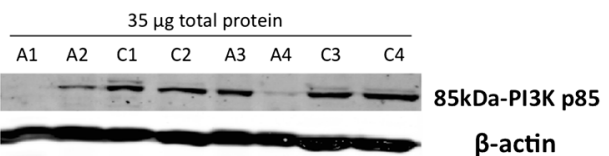

D

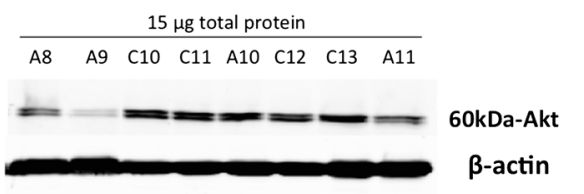

Figure 1 Quantification of (A) PI3K p85 and (C) Akt protein expression in fusiform gyrus of autism and control samples by Western blotting. Each sample was normalized to its $\beta$-actin. ${ }^{*} p=0.03$ for PI3K p85 and Akt, 2-tailed $t$ tests. Bars indicate mean \pm SE. Autism, $n=11$; control, $n=13$. The mean from two independent Western blots per sample was used for statistical analysis. (B) and (D) Representative Western blots of fusiform gyrus showing autism (A) and control (C) cases. $35 \mu \mathrm{g}$ for PI3K p85 and $15 \mu \mathrm{g}$ for Akt of total protein from each autism and control sample were loaded.

Reduced PSD-95 protein expression in idiopathic autism Because the Akt/mTOR pathway can influence protein synthesis at spines, and de-regulated mTOR has been associated with spine deficits in monogenic disorders with high rates of autism [2,3,36], PSD-95 protein expression, a marker of excitatory synapses, was examined in the fusiform gyrus of autism versus control subjects. Western blotting revealed a significant decrease in PSD95 protein levels ( ${ }^{*} \mathrm{p}=0.02$, Figure $4 \mathrm{~A}, \mathrm{~B} ; 2$-tailed $t$ test) in individuals with idiopathic autism versus controls.
Imbalance in TrkB protein isoforms in idiopathic autism The TrkB/Akt pathway is known to influence PSD-95 trafficking to spines [37]. Thus, differences in relative TrkB protein isoform levels in fusiform gyrus between autism and control groups were examined by Western blotting. A significant reduction in full-length TrkB (TrkB-FL)/truncated TrkB (TrkB-T1 + TrkB-Shc) isoform ratio and increase in the ratio of truncated TrkB isoforms/ TrkB-FL $\left(* * \mathrm{p}=0.002\right.$, Figure $5 \mathrm{~A} ;{ }^{* * *} \mathrm{p}=0.009$, Figure $5 \mathrm{~B} ; 2$ tailed $t$ tests) were observed in the fusiform gyrus of
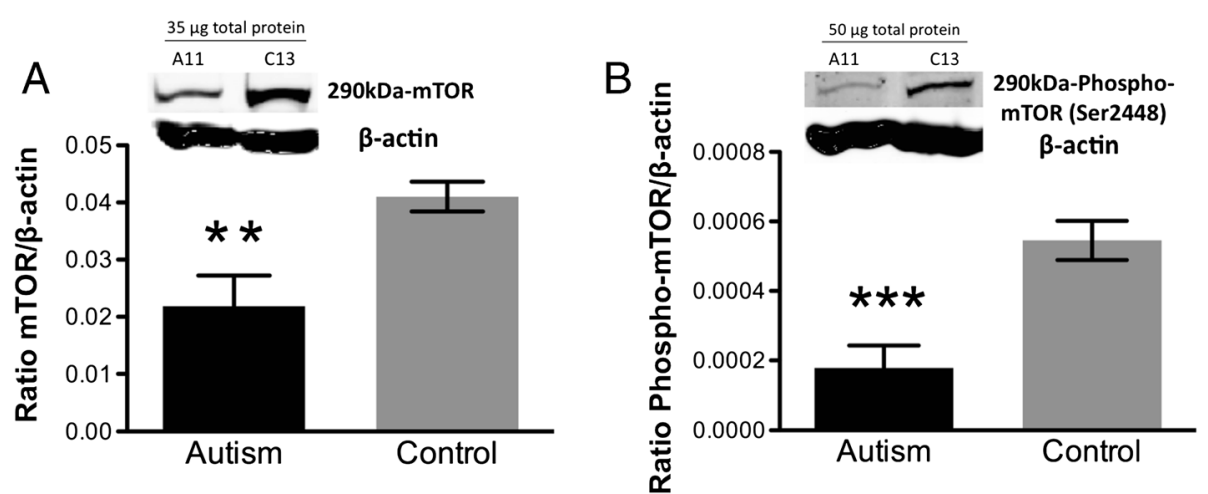

Figure 2 Quantification by Western blotting and representative Western blots of (A) total mTOR and (B) phospho-mTOR protein expression in autism versus control fusiform gyrus samples. Each sample was normalized to its $\beta$-actin. ${ }^{* *} p=0.003$ for $m T O R$, ${ }^{* * *} p=0.0003$ for phospho-mTOR, 2-tailed $t$ tests. Bars indicate mean \pm SE. Autism, $n=11$; control, $n=13$. The mean from two independent Western blots per sample was used for statistical analysis. $35 \mu \mathrm{g}$ for mTOR and $50 \mu \mathrm{g}$ for phospho-mTOR of total protein from each autism (A) and control (C) sample were loaded. 
A

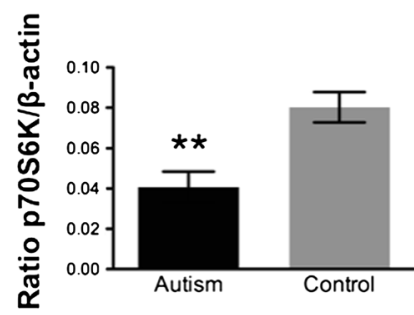

C

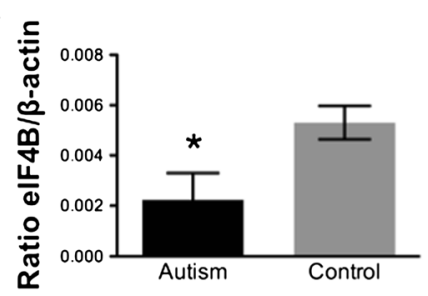

E

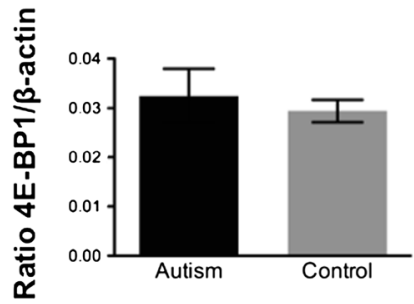

G

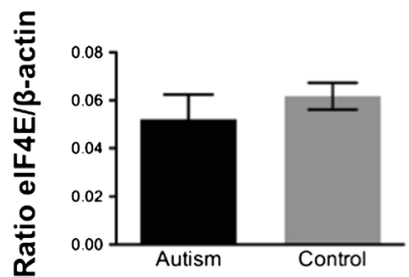

B

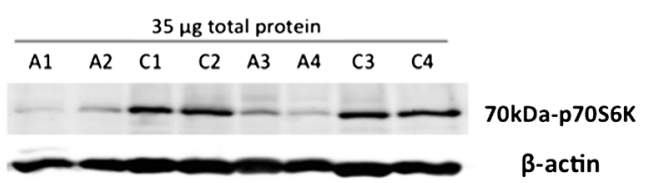

D

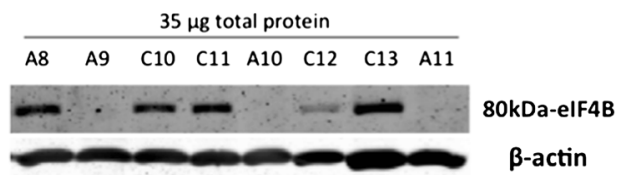

F
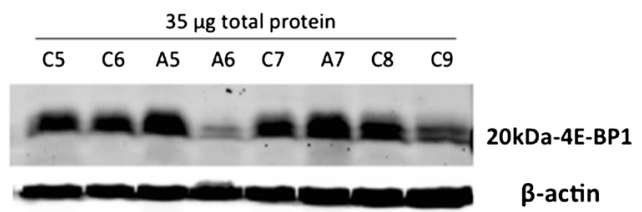

$\mathrm{H}$

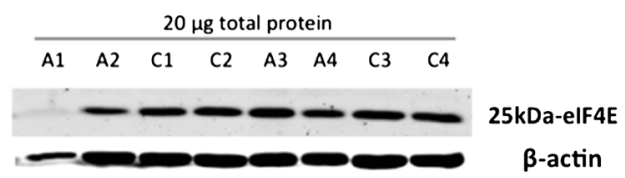

Figure 3 Quantification of (A) p70S6K, (C) elF4B, (E) 4E-BP1 and (G) elF4E protein expression in fusiform gyrus of autism and control samples by Western blotting. Each sample was normalized to its $\beta$-actin. ${ }^{* *} p=0.002$ for $p 7056 K,{ }^{*} p=0.02$ for elF4B, $p=0.6$ for $4 E-B P 1$ and $p=0.4$ for elF4E, 2-tailed $t$ tests. Bars indicate mean \pm SE. Autism, $n=11$; control, $n=13$. The mean from two independent Western blots per sample was used for statistical analysis. (B), (D), (F) and (H) Representative Western blots of fusiform gyrus showing autism (A) and control (C) cases. $35 \mu \mathrm{g}$ for p70S6K, elF4B and $4 \mathrm{E}-\mathrm{BP} 1$ and $20 \mathrm{\mu g}$ for elF4E of total protein from each autism and control sample were loaded.

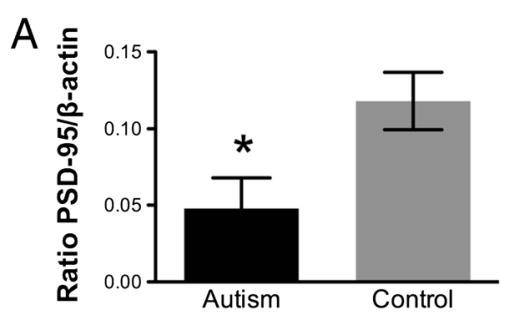

B

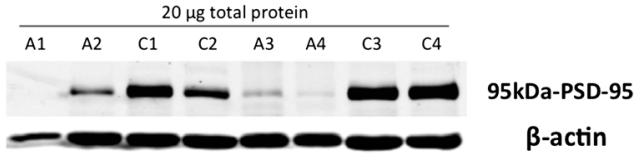

Figure 4 Quantification of (A) PSD-95 protein expression in fusiform gyrus of autism and control samples by Western blotting. Each sample was normalized to its $\beta$-actin. ${ }^{*} p=0.02$, 2-tailed $t$ test. Bars indicate mean \pm SE. Autism, $n=11$; control, $n=13$. The mean from three independent Western blots per sample was used for statistical analysis. (B) Representative Western blots of fusiform gyrus showing autism (A) and control (C) cases. $20 \mu \mathrm{g}$ of total protein from each autism and control sample were loaded. 

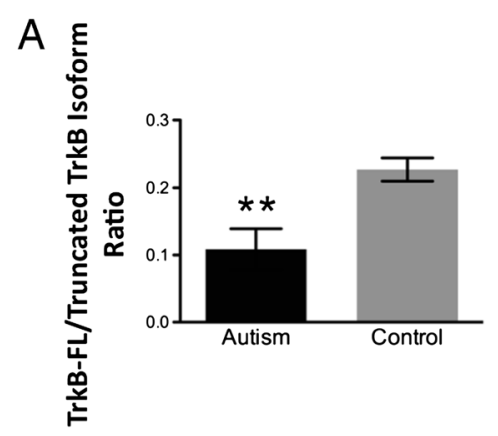

C

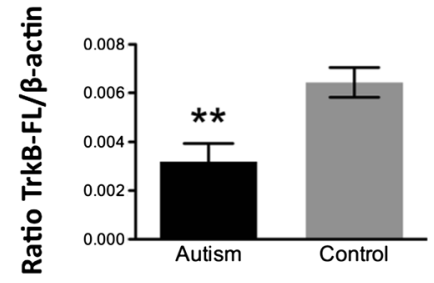

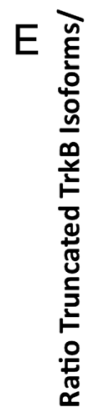

Figure 5 Quantification of (A) full-length (FL)/truncated and (B) truncated/full-length (FL) TrkB isoform protein ratios in fusiform gyrus of autism and control samples. ${ }^{* *} p=0.002$ and ${ }^{* *} p=0.009$, respectively, 2-tailed $t$ tests. Bars indicate mean $\pm S E$. Autism, $n=11 ;$ control, $n=13$. (C) Quantification of full-length (FL) TrkB and (E) truncated TrkB isoform protein expression in fusiform gyrus of autism and control samples by Western blotting. Each sample was normalized to its $\beta$-actin. ${ }^{* *} p=0.003$ for TrkB-FL and $p=0.09$ for truncated TrkB isoforms, 2-tailed $t$ tests. Bars indicate mean \pm SE. Autism, $n=11$; control, $n=13$. The mean from two independent Western blots per sample was used for statistical analysis. (D) and (F) Representative Western blots of fusiform gyrus showing autism (A) and control (C) cases. Lanes 2 to 5 : standard curve consisting of different amounts of total protein from a single normal human cortex sample. Lanes 6 to $13: 35 \mu \mathrm{g}$ of total protein from each autism and control sample. individuals with idiopathic autism versus controls. This may be due to significantly decreased TrkB-FL $(* * \mathrm{p}=$ 0.003 , Figure 5C,D; 2-tailed $t$ test) as well as a trend towards increased truncated $\operatorname{TrkB}(\mathrm{p}=0.09$, Figure $5 \mathrm{E}, \mathrm{F}$; 2 -tailed $t$ test). TrkB-FL and truncated TrkB are differentially expressed in different cell types: TrkB-FL is neuronal whereas truncated $\operatorname{TrkB}$ isoforms are widely expressed in glia. Therefore, we measured protein levels of GFAP (glial) and $\beta I I I-T u b u l i n$ (neuronal) markers. There were no significant differences in GFAP or BIII-Tubulin protein expression in the fusiform gyrus $(\mathrm{p}=0.4$, Figure $6 \mathrm{~A}, \mathrm{~B} ; \mathrm{p}=0.5$, Figure 6C,D; 2-tailed $t$ tests) between control and autism subjects, which precludes differential cell loss as a mechanism for TrkB isoform alterations. There were also no differences between groups in $\beta$-actin levels $(\mathrm{p}=0.7,2$-tailed $t$ test, data not shown), which were used to normalize samples on the Western blots.
No significant differences in TrkB isoform mRNA levels were found in the fusiform gyrus between control and autism subjects (TrkB-FL: $\mathrm{p}=0.1$; TrkB-T1: $\mathrm{p}=0.3$; TrkB-Shc: $\mathrm{p}=0.7$; 2-tailed $t$ tests; data not shown).

\section{Decreased mTOR signaling in VPA-exposed rats}

In this study, we specifically chose to examine idiopathic autism. As epigenetics are thought to play a key role in causing idiopathic autism, we also examined the brains of rats exposed to the HDAC inhibitor VPA in utero. We measured Akt, mTOR, S6K, and 4E-BP1 total and phosphorylated protein levels in VPA- versus salineexposed rat lateral temporal neocortices.

Western blotting revealed a statistically significant decrease in both total and phosphorylated Akt $\left({ }^{* * *} \mathrm{p}=0.002\right.$, Figure 7A; ** $\mathrm{p}=0.004$, Figure 8A; 2-tailed $t$ tests), mTOR ${ }^{* * * * *} \mathrm{p}<0.0001$, Figure $7 \mathrm{~B} ;{ }^{* * * * \mathrm{p}}<0.0001$, Figure $8 \mathrm{~B} ; 2$-tailed 

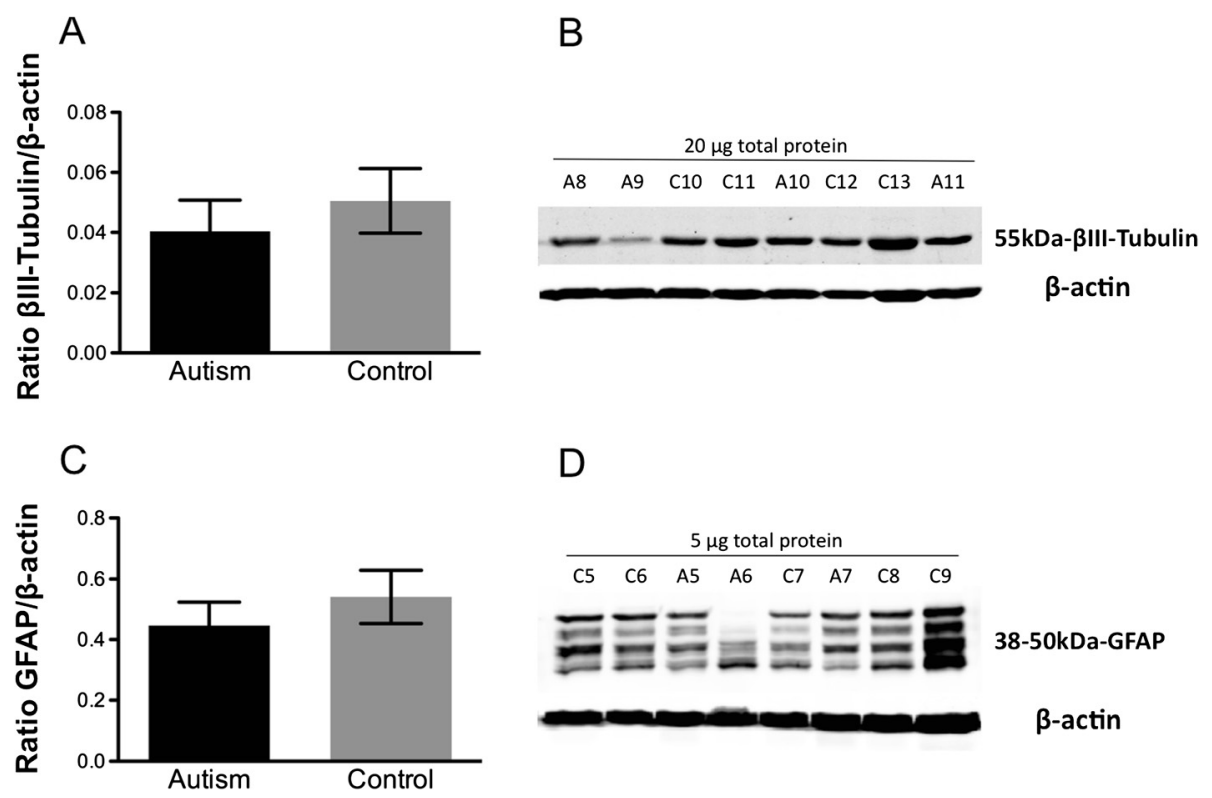

$\mathrm{D}$

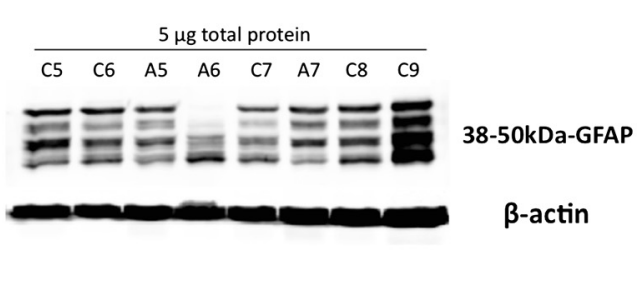

Figure 6 Quantification of (A) Beta-III Tubulin and (C) GFAP protein expression in fusiform gyrus of autism and control samples by Western blotting. Each sample was normalized to its $\beta$-actin. As reported by other studies [38,39], four bands ranging from $38 \mathrm{kDa}$ to $50 \mathrm{kDa}$ were detected for GFAP in all samples and quantified together. $p=0.5$ for $\beta$ Ill-tubulin, $p=0.4$ for GFAP, 2-tailed $t$ test. Bars indicate mean $\pm S E$. Autism, $n=11$; control, $n=13$. The mean from two independent Western blots per sample was used for statistical analysis. (B) and (D) Representative Western blots of fusiform gyrus showing autism (A) and control (C) cases. $20 \mu \mathrm{g}$ for Beta-III Tubulin and $5 \mu \mathrm{g}$ for GFAP of total protein from each autism and control sample were loaded.

$t$ tests $)$ and 4E-BP1 $(* * * \mathrm{p}<0.0001$, Figure 7D; $* * * \mathrm{p}<$ 0.0001 , Figure 8D; 2-tailed $t$ tests) in VPA-exposed rats compared to saline-exposed controls. However, only phosphorylated (*** $\mathrm{p}<0.0001$, Figure $8 \mathrm{C} ; 2$-tailed $t$ test) but not total ( $\mathrm{p}=0.6$, Figure $7 C$; 2 -tailed $t$ test) $\mathrm{S} 6$ protein expression was significantly reduced in VPA- versus salineexposed rats.

\section{Discussion}

Studies of single-gene disorders with a high prevalence of autism such as Rett syndrome (mutations in MeCP2), fragile X syndrome (mutations in FMR1), tuberous sclerosis (mutations in TSC1/TSC2), neurofibromatosis (mutations in NF1), and macrocephaly (mutations in PTEN), point to the Akt/mTOR pathway as a good candidate for involvement in autism pathogenesis [2-5,36,40,41]. In the present study, we demonstrate that, in contrast to fragile $\mathrm{X}$ syndrome, tuberous sclerosis, neurofibromatosis 1 and macrocephaly which exhibit increased mTOR pathway components $[2,3,5]$, the mTOR pathway is decreased in idiopathic autism. Our findings are consistent with previous reports of reduced mTOR pathway in Rett syndrome [36] and decreased Akt total protein and phosphorylation in frontal cerebral cortex from autistic patients [42]. This supports the idea that mTOR pathway deviations in either direction can adversely affect establishment, maintenance and function of neural networks and thus ultimately cause autism's cognitive and behavioural deficits [43].

As several of our subjects with autism exhibited seizures $(n=4)$, while others did not $(n=6)$, results from these two groups of patients were compared. No differences in levels of any of the proteins studied (PI3K p85, Akt, total and phosphorylated mTOR, TrkB isoforms, p70S6K, eIF4B or PSD-95) were found between autism cases with seizure disorder and those without $(\mathrm{p}>0.05$, 2 -tailed $t$ tests). This is consistent with our previous findings for BDNF [28]. BDNF mRNA is highly sensitive to seizures, and yet in that study, none of our autistic subjects with seizures (the same ones as used in this study) exhibited higher BDNF mRNA levels than those without.

mTOR regulates protein synthesis at synapses via two distinct downstream pathways which are responsible for promoting translation of different pools of mRNAs $[44,45]$. The p70S6K and eukaryotic initiation factor $4 \mathrm{~B}$ (eIF4B) cascade regulates translation of mRNAs encoding translational machinery components such as elongation and initiation factors and ribosomal proteins, while the eukaryotic initiation factor 4E-binding protein 1 (4E-BP1) and eukaryotic initiation factor 4E (eIF4E) pathway control translation of $5^{\prime}$ capped mRNAs coding for structural and functional synaptic proteins [46,47]. Single nucleotide insertions in the promoter of the mTOR effector eIF4E are 

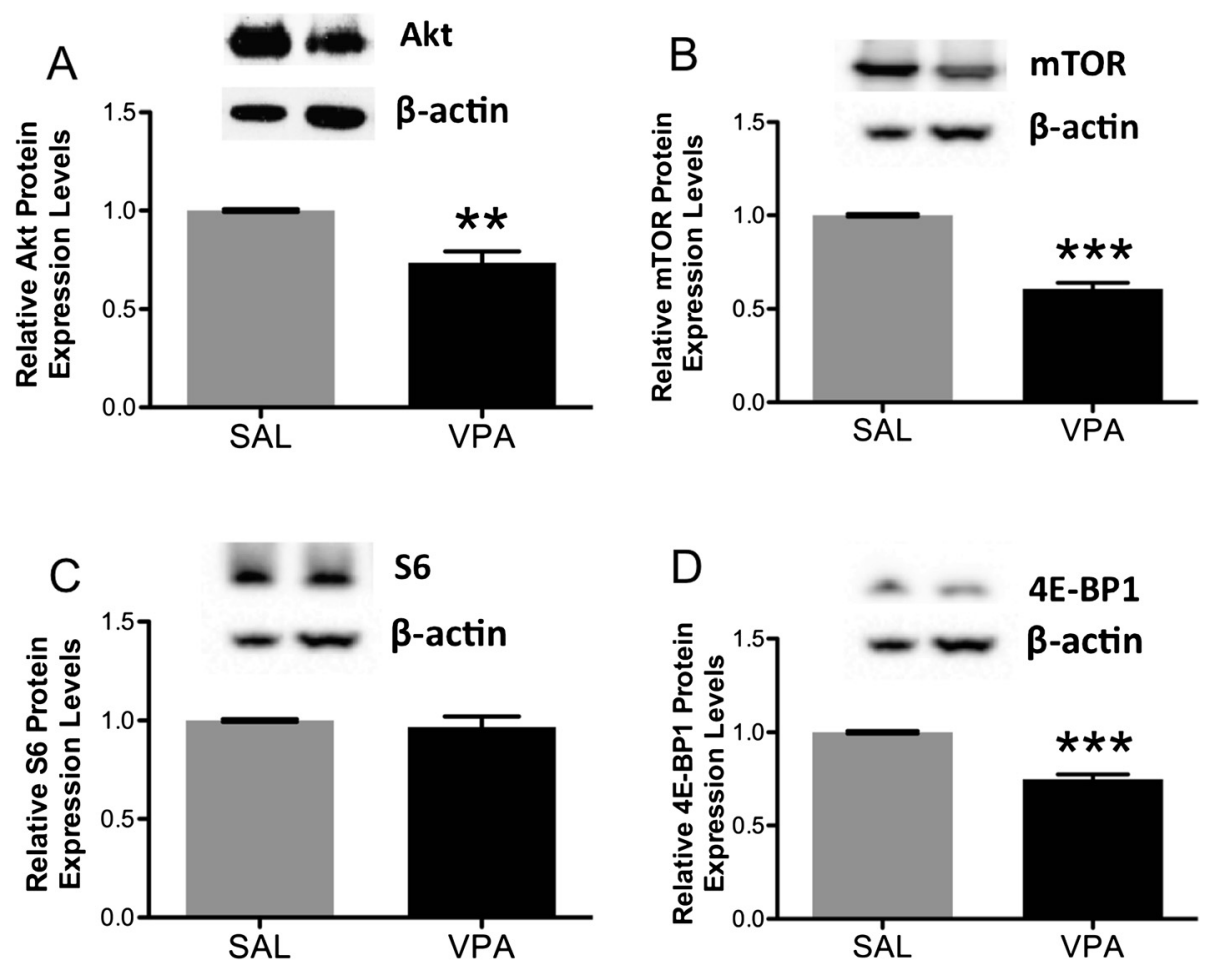

Figure 7 Quantification by Western blotting and representative Western blots of total (A) Akt, (B) mTOR, (C) S6 and (D) 4E-BP1 protein expression in VPA- versus saline (SAL)-exposed rat lateral temporal neocortices. Each sample was normalized to its $\beta$-actin, and VPA-exposed values were expressed relative to SAL-exposed. All $p$-values were calculated by 2-tailed $t$ test. Akt: ${ }^{* *} p=0.002, S A L, n=5 ; V P A, n=5 ; \quad$ TOR: ${ }^{* * *} p<$ $0.0001, S A L, n=8 ; V P A, n=8 ; S 6: p=0.5, S A L, n=8 ; V P A, n=8 ; 4 E-B P 1:{ }^{* *} p<0.0001, S A L, n=6 ; V P A, n=6$. Bars indicate mean $\pm S E$. The mean from three independent Western blots per sample was used for statistical analysis.

found in individuals with autism from two unrelated families [5], and linkage of autism to the eIF4E region on chromosome 4q shown in genome-wide association studies [48] suggest that this pathway may be preferentially affected in genetic causes of autism. Conversely, in our study, autistic subjects had significantly decreased p70S6K and eIF4B, while there were no changes in $4 \mathrm{E}-\mathrm{BP} 1$ or eIF4E in these patients, pointing to specific deficits in mTOR-dependent translation via the p70S6K/S6 pathway in idiopathic autism.

Overall, nine of our eleven autism subjects, regardless of whether they had concurrent seizure disorder, exhibited decreases throughout the mTOR pathway (Table 3). The direction of change is uniform for each subject, suggesting coordinated or feedback regulation of the pathway. Our findings demonstrate that disruptions in mTOR and its signaling cascade components are widespread in the autism population and not limited to genetic forms of autism.

In support of this evidence, our animal data point to epigenetic mechanisms as a likely underlying cause of these disruptions. We are the first to report that maternal exposure to the anticonvulsant VPA, an HDAC inhibitor, results in decreased mTOR signaling in lateral temporal neocortices of rats. Significantly down-regulated protein levels of mTOR as well as its upstream/downstream effectors were associated with a significant reduction in the overall amount of social play behaviors and an attenuated response to playful attacks in VPA- versus saline-exposed control rats [34,49], corroborating the hypothesis that reduced mTOR pathway signaling contributes to autistic behaviors.

In contrast to idiopathic autism which exhibits only S6 pathway deficits, both mTOR downstream effector cascades appear to be affected in VPA-exposed rats, as deficits were found in phosphorylated S6 and 4E-BP1. It is possible that these differences in down-regulated mTOR effectors between rat and human may specifically underlie autistic-like behavior caused by VPA treatment.

A consequence of dysfunctional mTOR signaling is deficits in spine protein translation and changes in spine morphology, density and dynamics [3,36]. Abnormal spine density and morphology have been reported in cortical neurons from autistic subjects $[7,50]$. Interestingly, we observed that decreased mTOR was associated with a significant reduction of PSD-95, a key postsynaptic density 

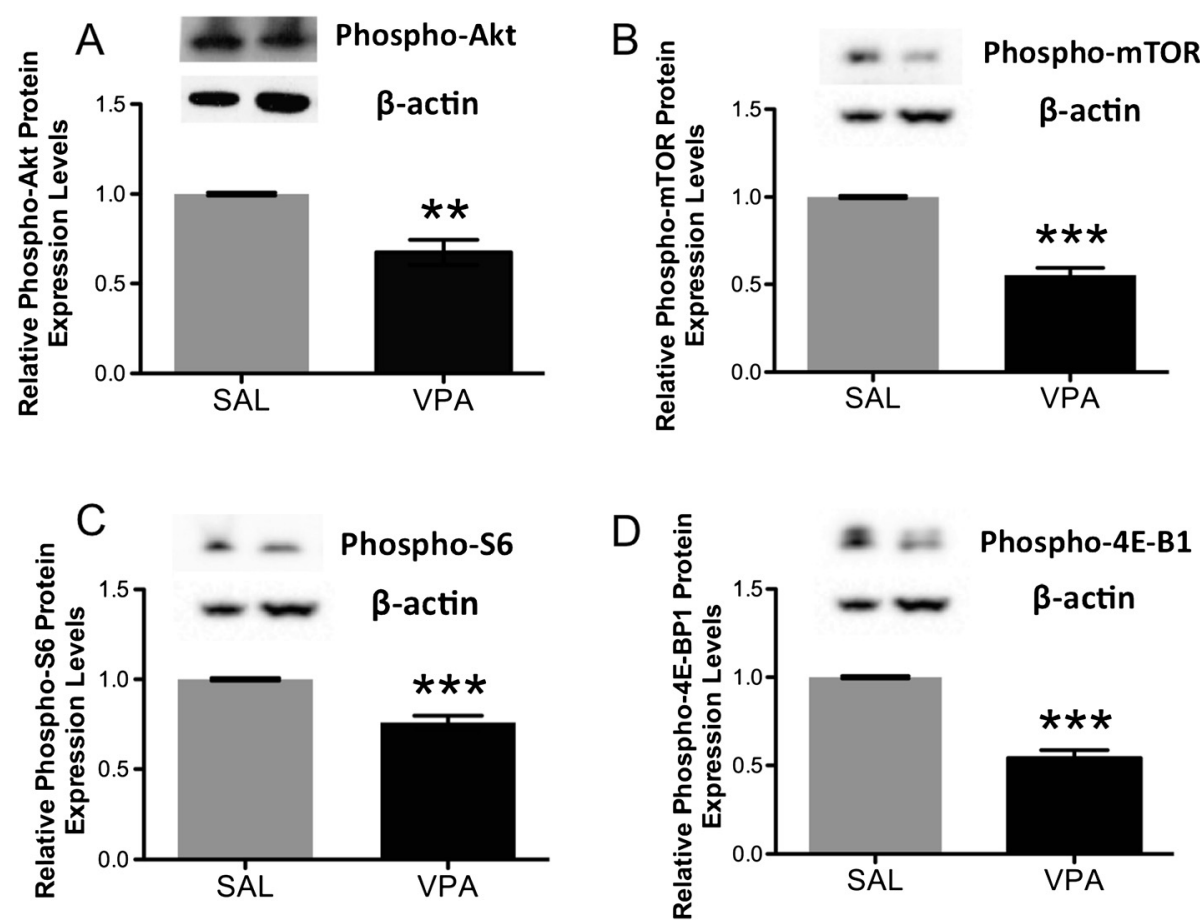

Figure 8 Quantification by Western blotting and representative Western blots of phosphorylated (A) Akt, (B) mTOR, (C) S6 and (D) 4E-BP1 protein expression in VPA- versus saline (SAL)-exposed rat lateral temporal neocortices. Each sample was normalized to its $\beta$-actin, and VPA-exposed values were expressed relative to SAL-exposed. All p-values were calculated by 2-tailed $t$ test. Phospho-Akt: ${ }^{* *} p=0.004, S A L$, $n=4$; VPA, $n=4$; phospho-mTOR: ${ }^{* *} p<0.0001$, SAL, $n=8$; VPA, $n=8$; phospho-S6: ${ }^{* *} p<0.0001$, SAL, $n=8 ;$ VPA, $n=8$; phospho-4E-BP1: *** $p<$ $0.0001, S A L, n=6 ; V P A, n=6$. Bars indicate mean $\pm S E$. The mean from three independent Western blots per sample was used for statistical analysis.

organizing molecule, in autistic subjects compared to controls. There are several mechanisms at work which might impact levels of PSD-95. The high-affinity brain-derived neurotrophic factor (BDNF) receptor TrkB regulates trafficking of PSD-95 at synapses via PI3K-Akt [37]. Interestingly, $\operatorname{TrkB}$ involvement in autism pathogenesis is substantiated by the finding of an association between trkB (nTrk2) gene variants and autism [51]. Consistently, we discovered significantly decreased protein levels of fulllength TrkB (TrkB-FL), a trend towards increased truncated TrkB isoform protein levels and significantly altered TrkB isoform ratios in autism versus control subjects, supporting a TrkB isoform imbalance in autism similar to other neuropsychiatric disorders such as schizophrenia $[52,53]$. By interfering with PSD-95 transport at synapses via PI3K/Akt, decreased TrkB-FL may negatively affect spines and thus might impair neural networks which subserve higher cognitive functions and behavior. Reduced TrkB might also contribute to the Akt/mTOR pathway down-regulation seen in idiopathic autism, since TrkB-FL contains the intracellular catalytic tyrosine kinase domain needed to activate TrkB-mediated signaling cascades, including the Akt/mTOR pathway, upon BDNF binding [54]. Additionally, truncated TrkB isoforms, which lack the tyrosine kinase activity and thus can only bind and sequester BDNF but cannot activate downstream signaling cascades [55,56], could act as negative regulators by trapping BDNF or by forming heterodimers with TrkB-FL receptors [57-59], and further down-regulate the Akt/ mTOR pathway.

TrkB-FL is expressed almost exclusively in pyramidal neurons and interneurons [60-62], whereas truncated isoforms are found in both neurons and glia [63,64]. However, no differences in either GFAP or BIII-Tubulin levels between autism and control subjects were detected, demonstrating that these TrkB isoform imbalances are not due to a shift in the proportion of neurons versus glia. Also, as no alterations were observed in TrkB isoform mRNA, it is likely that translational and/or post-translational mechanisms may contribute to the abnormal ratio of TrkB isoforms seen in the autistic brain.

In summary, our study is the first to demonstrate major decreases in protein expression and phosphorylation for mTOR and components of its downstream signaling pathways in subjects with idiopathic autism. These data demonstrate that deficits in this pathway are widespread in idiopathic autism and that up- or downregulation of this pathway can have equally disruptive 
Table 3 Distribution of analyzed protein targets from autism subjects relative to controls

\begin{tabular}{|c|c|c|c|c|c|c|c|c|c|c|c|}
\hline & \multicolumn{7}{|c|}{ Autism patients with no seizure disorder } & \multicolumn{4}{|c|}{ Autism patients with seizure disorder } \\
\hline & $\begin{array}{l}\text { AN01093 } \\
\text { (A1) }\end{array}$ & $\begin{array}{l}\text { AN00764 } \\
\text { (A3) }\end{array}$ & $\begin{array}{l}\text { AN00493 } \\
\text { (A6) }\end{array}$ & $\begin{array}{l}\text { UMB1182 } \\
\text { (A9) }\end{array}$ & $\begin{array}{l}\text { AN06420 } \\
\text { (A5) }\end{array}$ & $\begin{array}{l}\text { UMB797 } \\
\text { (A8) }\end{array}$ & $\begin{array}{l}\text { AN08873 } \\
\text { (A7) }\end{array}$ & $\begin{array}{l}\text { UMB1174 } \\
\text { (A2) }\end{array}$ & $\begin{array}{l}\text { AN08792 } \\
\text { (A4) }\end{array}$ & $\begin{array}{l}\text { AN16641 } \\
\text { (A10) }\end{array}$ & $\begin{array}{l}\text { AN16615 } \\
\text { (A11) }\end{array}$ \\
\hline TrkB-FL & $-2.0 S D$ & $-1.5 S D$ & $-2.0 S D$ & $-1.5 S D$ & $0.5 \mathrm{SD}$ & $-0.5 S D$ & $0.5 \mathrm{SD}$ & $-2.0 S D$ & $-2.0 S D$ & $-1.5 S D$ & $-1.5 S D$ \\
\hline PI3K p85 & $-2.0 S D$ & $-1.5 S D$ & $-2.0 S D$ & $-2.0 S D$ & $0.5 \mathrm{SD}$ & $-0.5 S D$ & $0.5 \mathrm{SD}$ & $-2.0 S D$ & $-2.0 S D$ & $1.5 \mathrm{SD}$ & $-1.5 S D$ \\
\hline Akt & $-2.0 S D$ & $-0.5 S D$ & $-1.5 S D$ & $-2.0 S D$ & $1.5 \mathrm{SD}$ & $-0.5 S D$ & $0.5 \mathrm{SD}$ & $-1.5 S D$ & $-1.5 S D$ & $-0.5 S D$ & $-1.5 S D$ \\
\hline mTOR & $-2.0 S D$ & $-2.0 S D$ & $-2.0 S D$ & $-2.0 S D$ & $1.5 \mathrm{SD}$ & $-0.5 S D$ & $0.5 \mathrm{SD}$ & $-2.0 S D$ & $-2.0 S D$ & $-1.5 S D$ & $-2.0 S D$ \\
\hline Phospho-mTOR & $-1.5 S D$ & $-2.0 S D$ & $-2.0 S D$ & $-2.0 S D$ & $0.5 \mathrm{SD}$ & $-0.5 S D$ & $-0.5 S D$ & $-2.0 S D$ & $-2.0 S D$ & $-2.0 S D$ & $-2.0 S D$ \\
\hline p70 S6 Kinase & $-2.0 S D$ & $-1.5 S D$ & $-1.5 S D$ & $-2.0 S D$ & $0.5 \mathrm{SD}$ & $-0.5 S D$ & $-0.5 S D$ & $-1.5 S D$ & $-2.0 S D$ & $-1.5 S D$ & $-1.5 S D$ \\
\hline elF4B & $-2.0 S D$ & $-2.0 S D$ & $-2.0 S D$ & $-1.5 S D$ & $1.5 \mathrm{SD}$ & $2.0 \mathrm{SD}$ & $-0.5 S D$ & $-1.5 S D$ & $-2.0 S D$ & $-2.0 S D$ & $-2.0 S D$ \\
\hline PSD-95 & $-1.5 S D$ & $-1.5 S D$ & $-1.5 S D$ & $-1.5 S D$ & $0.5 \mathrm{SD}$ & $0.5 \mathrm{SD}$ & $0.5 \mathrm{SD}$ & $-1.5 S D$ & $-1.5 S D$ & $-1.5 S D$ & $-1.5 S D$ \\
\hline
\end{tabular}

SD $=$ Standard deviation. The mean of each target for the control group was used as a reference to calculate the corresponding standard deviation values for each target. Bold-ltalics $=0.5-2.0$ standard deviations less than the mean of controls. Not Bold = 0.5-2.0 standard deviations greater than the mean of controls. 
consequences. Notably, mTOR pathway deficits are supported by similar alterations in VPA-exposed rats, pointing to epigenetic mechanisms as the underlying molecular substrate of these disruptions. Despite minor differences in down-regulated mTOR cascade effectors, our human and animal data identify dysfunctional mTOR as a common molecular mechanism underlying autistic traits and suggest that a disruption of this pathway in either direction can have adverse consequences for dendritic spines, as supported by decreased PSD-95, and thus ultimately for synaptic development and function. In conclusion, our present findings highlight that decreased mTOR is likely to adversely affect spines and ultimately cortical circuits implicated in higher cognitive functions and behavior causing autistic phenotypes.

\section{Competing interests}

The authors declare that they have no competing interests.

\section{Acknowledgements}

This work was supported by a studentship from the Autism Research Training (ART) Program to CN and by the Alberta Children's Hospital Research Institute (ACHRI) and the Canadian Institutes of Health Research (CIHR) Fellowship Program. We gratefully acknowledge the Autism Speaks' Autism Tissue Program, the Harvard Brain Tissue Resource Center and the NICHD Brain and Tissue Bank for providing brain tissues for this study.

\section{Author details}

'Department of Psychiatry \& Behavioural Neurosciences, McMaster University, 1280 Main Street West, Hamilton, ON L8S 4K1, Canada. ${ }^{2}$ Departments of Paediatrics \& Clinical Neurosciences, Alberta Children's Hospital Research Institute, University of Calgary, Calgary, AB T3B 6A8, Canada.

Received: 31 December 2014 Accepted: 4 January 2015

Published online: 20 January 2015

\section{References}

1. American Psychiatric Association (1994) Diagnostic and Statistical Manual of Mental Disorders, 5th edn. American Psychiatric Press, Washington, DC

2. Kelleher RJ 3rd, Bear MF (2008) The autistic neuron: troubled translation? Cell 135:401-406

3. Troca-Marin JA, Alves-Sampaio A, Montesinos ML (2012) Deregulated mTORmediated translation in intellectual disability. Prog Neurobiol 96:268-282

4. Levitt P, Campbell DB (2009) The genetic and neurobiologic compass points toward common signaling dysfunctions in autism spectrum disorders. J Clin Invest 119:747-754

5. Ehninger D, Silva AJ (2011) Rapamycin for treating Tuberous sclerosis and Autism spectrum disorders. Trends Mol Med 17:78-87

6. Gkogkas CG, Khoutorsky A, Ran I, Rampakakis E, Nevarko T, Weatherill DB et al (2013) Autism-related deficits via dysregulated elF4E-dependent translational control. Nature 493:371-377

7. Hutsler JJ, Zhang H (2010) Increased dendritic spine densities on cortical projection neurons in autism spectrum disorders. Brain Res 1309:83-94

8. Löscher V (2002) Basic pharmacology of valproate. A review after 35 years of clinical use for the treatment of epilepsy. CNS Drugs 16:669-694

9. Lambert PA, Carraz G, Borselli S, Bouchardy M (1975) Dipropylacetamide in the treatment of manic-depressive psychosis. Encéphale 1:25-31

10. Emrich HM, von Zerssen D, Kissling W, Möller HG, Windorfer A (1980) Effect of sodium valproate on mania. The GABA-hypothesis of affective disorders. Acta Psychiatr Nervenkr 229:1-16

11. Christianson AL, Chesler N, Kromberg JG (1994) Fetal valproate syndrome: clinical and neuro-developmental features in two sibling pairs. Dev Med Child Neurol 36:361-369

12. Moore SJ, Turnpenny P, Quinn A, Glover S, Lloyd DJ, Montgomery T et al (2000) A clinical study of 57 children with fetal anticonvulsant syndromes. J Med Genet 37:489-497
13. Christensen J, Gronborg TK, Sorensen MJ, Schendel D, Parner ET, Pedersen LH et al (2013) Prenatal exposure and risk of autism spectrum disorders and childhood autism. JAMA 309:1696-1703

14. Markram H, Rinaldi T, Markram K (2007) The intense world syndrome- an alternative hypothesis for autism. Front Neurosci 1:77-96

15. Stanton ME, Peloso E, Brown KL, Rodier P (2007) Discrimination learning and reversal of the conditioned eyeblink reflex in a rodent model of autism. Behav Brain Res 176:133-140

16. Roulett Fl, Wollaston L, Decatanzaro D, Foster JA (2010) Behavioural and molecular changes in the mouse in response to prenatal exposure to the anti-epileptic drug valproic acid. Neuroscience 170:514-522

17. Kataoka S, Takuma K, Hara Y, Maeda Y, Ago Y, Matsuda T (2013) Autism-like behaviours with transient histone hyperacetylation in mice treated prenatally with valproic acid. Int J Neuropsychopharmacol 16:91-103

18. Schneider T, Przewlocki R (2005) Behavioural alterations in rats prenatally exposed to valproic acid: animal model of autism. Neuropsychopharmacology 30:80-89

19. Markram K, Rinaldi T, La Mendola D, Sandi C, Markram H (2008) Abnormal fear conditioning and amygdala processing in an animal model of autism. Neuropsychopharmacology 33:901-912

20. Rodier PM, Ingram JL, Tisdale B, Croog VJ (1997) Linking etiologies in humans and animal models: studies of autism. Reprod Toxicol 11:417-422

21. Ingram JL, Peckham SM, Tisdale B, Rodier PM (2000) Prenatal exposure of rats to valproic acid reproduces the cerebellar anomalies associated with autism. Neurotoxicol Teratol 22:319-324

22. Narita N, Kato M, Tazoe M, Miyazaki K, Narita M, Okado N (2002) Increased monoamine concentration in the brain and blood of fetal thalidomide- and valproic acid-exposed rat: putative animal models for autism. Pediatr Res 52:576-579

23. Kolozsi E, Mackenzie RN, Roulett Fl, deCatanzaro D, Foster JA (2009) Prenatal exposure to valproic acid leads to reduced expression of synptic adhesion molecule neuroligin 3 in mice. Neuroscience 163:1201-1210

24. Rinaldi T, Silberberg G, Markram H (2008) Hyperconnectivity of local neocortical microcircuitry induced by prenatal exposure to valproic acid. Cereb Cortex 18:763-770

25. Rinaldi T, Perrodin C, Markram H (2008) Hyper-connectivity and hyperplasticity in the medial prefrontal cortex in the valproic acid animal model of autism. Front Neural Circuits 2:4

26. Schanen NC (2006) Epigenetics of autism spectrum disorders. Hum Mol Genet 2:138-150

27. Wong CC, Meaburn EL, Ronald A, Price TS, Jeffries AR, Schwalkwyk LC et al (2014) Methylomic analysis of monozygotic twins discordant for autism spectrum disorder and related behavioural traits. Mol Psychiatry 19:495-503

28. Garcia KLP, Guanhua Y, Nicolini C, Michalski B, Garzon D, Chiu VS et al (2012) Altered balance of proteolytic forms of pro-brain-derived neurotrophic factor in autism. J Neuropathol Exp Neurol 71:289-297

29. Boucher J, Lewis V (1992) Unfamiliar face recognition in relatively able autistic children. J Child Psychol Psychiatry 33:843-859

30. Allison T, Ginter H, McCarthy G, Nobre AC, Puce A, Luby M et al (1994) Face recognition in human extrastriate cortex. J Neurophysiol 71:821-825

31. Gauthier I, Anderson AW, Tarr MJ, Skudlarski P, Gore JC (1997) Levels of categorization in visual recognition studied using functional magnetic resonance imaging. Curr Biol 7:645-651

32. Schultz RT, Gauthier I, Klin A, Fulbright RK, Anderson AW, Volkmar F et al (2000) Abnormal ventral temporal cortical activity during face discrimination among individuals with autism and Asperger syndrome. Arch Gen Psychiatry 57:331-340

33. Lord C, Rutter M, Le Couteur A (1994) Autism diagnostic interview-revised. A revised version of a diagnostic interview for caregivers of individuals with possible pervasive developmental disorders. Autism Dev Dis 24:659-685

34. Chomiak T, Karnik V, Block E, Hu B (2010) Altering the trajectory of early postnatal cortical development can lead to structural and behavioural features of autism. BMC Neurosci 11:102

35. Menna E, Zambetti S, Morini R, Donzelli A, Disanza A, Calvigioni D et al (2013) Eps8 controls dendritic spine density and synaptic plasticity through its actin-capping activity. EMBO J 32:1730-1744

36. Ricciardi S, Boggio EM, Grosso S, Lonetti G, Forlani G, Stefanelli G et al (2011) Reduced AKT/mTOR signaling and protein synthesis dysregulation in a Rett syndrome animal model. Hum Mol Genet 20:1182-1196

37. Yoshii A, Constantine-Paton M (2010) Postsynaptic BDNF-TrkB signaling in synapse maturation, plasticity, and disease. Dev Neurobiol 70:304-322 
38. Newcombe J, Woodroofe MN, Cuzner ML (1986) Distribution of glial fibrillary acidic protein in gliosed human white matter. J Neurochem 47:1713-1719

39. Fatemi SH, Folsom TD (2011) Dysregulation of fragile X mental retardation protein and metabotropic glutamate receptor 5 in superior frontal cortex of individuals with autism: a postmortem brain study. Mol Autism 2:6

40. Bourgeron T (2009) A synaptic trek to autism. Curr Opin Neurobiol 19:231-234

41. Hoeffer CA, Klann E (2010) mTOR signaling: at the crossroads of plasticity, memory and disease. Trends Neurosci 33:67-75

42. Sheikh AM, Malik M, Wen G, Chauhan A, Chauhan V, Gong CX et al (2010) BDNF-Akt-Bcl2 antiapoptotic signaling pathway is compromised in the brain of autistic subjects. J Neurosci Res 88:2641-2647

43. Zoghbi HY, Bear MF (2012) Synaptic dysfunction in neurodevelopmental disorders associated with autism and intellectual disabilities. Cold Spring Harb Perspect Biol 4(3):a009886

44. Hay N, Sonenberg N (2004) Upstream and downstream of mTOR. Genes Dev 18:1926-1945

45. Jaworski J, Spangler S, Seeburg DP, Hoogenraad CC, Sheng M (2005) Control of dendritic arborization by the phosphoinositide-3'-kinase-Aktmammalian target of rapamycin pathway. J Neurosci 25:11300-11312

46. Santos AR, Comprido D, Duarte CB (2010) Regulation of local translation at the synapse by BDNF. Prog Neurobiol 92:505-516

47. Santini E, Klann E (2011) Dysregulated mTORC1-dependent translationa control: From brain disorders to psychoactive drugs. Front Behav Neurosci 5:76

48. Neves-Pereira M, Müller B, Massie D, Williams JH, O'Brien PC, Hughes A et al (2009) Deregulation of ElF4E: A novel mechanism for autism. J Med Genet 46:759-765

49. Ahn Y, Narous M, Tobias R, Hu B, Rho JM (2012) Alterations in social behavior and mTOR signaling in the valproic acid-induced model of autism spectrum disorder, Program No. 861.21. 2012 Neuroscience Meeting Planner. Society for Neuroscience, New Orleans, LA, Online

50. Williams RS, Hauser SL, Purpura DP, DeLong GR, Swisher CN (1980) Autism and mental retardation: neuropathologic studies performed in four retarded persons with autistic behavior. Arch Neurol 37:749-753

51. Correia $C T$, Coutinho AM, Sequeira AF, Sousa IG, Lourenço Venda L, Almeida JP et al (2010) Increased BDNF levels and NTRK2 gene association suggest a disruption of BDNF/TrkB signaling in autism. Genes Brain Behav 9:841-848

52. Weickert CS, Ligons DL, Romanczyk T, Ungaro G, Hyde TM, Herman MM et al (2005) Reductions in neurotrophin receptor mRNAs in the prefrontal cortex of patients with schizophrenia. Mol Psychiatry 10:637-650

53. Pillai A, Mahadik SP (2008) Increased truncated TrkB receptor expression and decreased BDNF/TrkB signaling in the frontal cortex of reeler mouse model of schizophrenia. Schizophr Res 100:325-333

54. Waterhouse EG, Xu B (2009) New insights into the role of brain-derived neurotrophic factor in synaptic plasticity. Mol Cell Neurosci 42:81-89

55. Klein R, Conway D, Parada LF, Barbacid M (1990) The trkB tyrosine protein kinase gene codes for a second neurogenic receptor that lacks the catalytic kinase domain. Cell 61:647-656

56. Wong J, Rothmond DA, Webster MJ, Weickert C (2013) Increases in two truncated TrkB isoforms in the prefrontal cortex of people with schizophrenia. Schizophr Bull 39:130-140

57. Eide FF, Vining ER, Eide BL, Zang K, Wang XY, Reichardt LF (1996) Naturally occurring truncated trkB receptors have dominant inhibitory effects on brain-derived neurotrophic factor signaling. J Neurosci 16:3123-3129

58. Haapasalo A, Koponen E, Hoppe E, Wong G, Castrén E (2001) Truncated trkB.T1 is dominant negative inhibitor of trkB.TK + -mediated cell survival. Biochem Biophys Res Commun 280:1352-1358

59. Stoilov P, Castren E, Stamm S (2002) Analysis of the human TrkB gene genomic organization reveals novel TrkB isoforms, unusual gene length, and splicing mechanism. Biochem Biophys Res Commun 290:1054-1065

60. Klein R, Parada LF, Coulier F, Barbacid M (1989) TrkB, a novel tyrosine protein kinase receptor expressed during mouse neural development. EMBO J 8:3701-3709

61. Klein R, Nanduri V, Jing SA, Lamballe F, Tapley P, Bryant S et al (1991) The trkB tyrosine protein kinase is a receptor for brain-derived neurotrophic factor and neurotrophin-3. Cell 66:395-403
62. Rose CR, Blum R, Pichler B, Lepier A, Kafitz KW, Konnerth A (2003) Truncated TrkB-T1 mediates neurotrophin-evoked calcium signaling in glia cells. Nature 426:74-78

63. Romanczyk TB, Weickert CS, Webster MJ, Herman MM, Akil M, Kleinman JE (2002) Alterations in trkB mRNA in the human prefrontal cortex throughout the lifespan. Eur J Neurosci 15:269-280

64. Ohira K, Hayashi M (2003) Expression of TrkB subtypes in the adult monkey cerebellar cortex. J Chem Neuroanat 25:175-183

\section{Submit your next manuscript to BioMed Central and take full advantage of:}

- Convenient online submission

- Thorough peer review

- No space constraints or color figure charges

- Immediate publication on acceptance

- Inclusion in PubMed, CAS, Scopus and Google Scholar

- Research which is freely available for redistribution 